\title{
TRADUCCIÓN DE SÍ. ENTRE LITERATURA MENOR, EXTRATERRITORIALIDAD Y 'BILINGUISM' '
}

\author{
Sigrid Weigel \\ Leibniz-Zentrum für Literatur- und Kulturforschung \\ Berlín, Alemania \\ siweigel@aol.com
}

RESUMEN / ABSTRACT

La traducción de sí, una expresión intrínsecamente ambivalente, lejos de ser un tema reservado a la expertise de unos pocos iniciados, es un concepto que debido a su posición de bisagra tiene un considerable rendimiento para la discusión filosófica, literaria y psicoanalítica. A partir de un examen de las teorías vigentes de la traducción y de la perspectiva de las literaturas menores se debate el problema de la hegemonía entre las lenguas y de la extraterritorialidad. La revisión del concepto del hombre traducido permite examinar el posible aporte del concepto bilingüismo y de re-writing al problema de la traducción de sí. A propósito de la idea de una traducción sin original se introduce la lógica del nachträglich como una vía para pensar las relaciones lógicas entre textos y lenguas.

PALABRAS ClaVE: traducción de sí, literatura menor, extraterritorialidad, bilingüismo.

\section{SELFTRANSLATION. BETWEEN MINOR LITERATURE, EXTRATERRITORIALITY AND 'BILINGUISM'}

Selftranslation, an intrinsically ambivalent expression, far from being a subject reserved for the expertise of a few initiates, is a concept that due to its hinge position has a considerable yield for philosophical, literary and psychoanalytical discussion. From an examination of the current theories of translation and the perspective of minor literatures, the problem of

1 Se trata de una traducción reelaborada y reescrita de mi artículo "Self-translation and its discontent. Or: The Translational Work Lost in the Theory of Bilingualism". En Migrating Histories of Art. Self-Translation of a Discipline. Ed. Maria Teresa Costa/Hans Christian Hönes. Berlin/Boston, 2019, pp. 21-35. Traducción de Niklas Bornhauser. 
the hegemony between languages and of extraterritoriality is discussed. The revision of the concept of the translated man allows us to examine the possible contribution of the concept of bilingualism and re-writing to the problem of translation itself. In relation to the idea of a translation without an original, the logic of nachträglich is introduced as a way of thinking about the logical relations between texts and languages.

KEYWORDS: selftranslation, minor literature, extraterritoriality, bilinguism.

Recepción: 13/11/2020

Aprobación: 16/12/2020

La palabra traducción de sí se caracteriza por una ambivalencia semántica significativa. En el registro de los conceptos filosóficos se refiere a la traducción de un texto propio a otra lengua. Pero también puede entenderse como la traducción del sí mismo, es decir, la transposición del sí mismo en otro contexto lingüístico-cultural, respectivamente, en un sí mismo que habita otra lengua. De esta ambivalencia emergen algunas preguntas de interés: ¿Cómo se comporta lo uno respecto de lo otro? ¿Qué efectos temporiza la transferencia de un texto propio hacia otra lengua en el modo de expresión de esbozos y reflexiones propias, en la forma de escribir y en la retórica, en el argumento y a quién está dirigido? Y, ¿cómo repercute la proximidad o distancia cultural, cómo repercute la pertenencia o ajenidad en la figura [Gestalt] del texto traducido? La mayoría de los trabajos sobre la traducción de sí, no obstante, se concentran en uno de ambos aspectos. O investigan la relación entre el original y el texto traducido con miras a sus respectivas características o diferencias, o tematizan la posición del autor y su lugar entre diferentes culturas.

\section{EL MALESTAR EN LA TRADUCCIÓN DE SÍ - LA PERSPECTIVA DE LAS LITERATURAS MENORES}

'Against translation' es el título de un artículo tan influyente como controversial, citado con frecuencia, publicado el año 2002, en el que el poeta, traductor y crítico escocés Christopher Whyte discute el problema de la hegemonía lingüística. En él, de manera acentuada, defiende la tesis de que "the practise of self-translation is never innocent" (69). Probablemente debido a su título provocador, pero sobre todo debido al gesto retórico de la negación radical, el artículo ha sido recepcionado como cuestionamiento fundamental de la 
traducción de sí, incluso como ataque contra ésta. No obstante, una lectura más precisa muestra que se trata de otra cosa, a saber, de la problematización de la práctica de las traducciones de sí desde una posición que puede ser circunscrita de la mejor manera -con Deleuze/Guattari en Kafka: Pour une literature mineure (1975)-como perspectiva de una literature mineure, una literatura menor. En Christoph White se trata de poesía en escocés-gaélico, la lengua de una minoría ${ }^{2}$ en un país en el que se habla una lengua mayor, incluso una lengua abrumadoramente mayor que se ha impuesto como idioma de la comunicación internacional. El artículo de Whyte se dirige contra el peligro de que una poesía escrita en una lengua perteneciente a una minoría precisamente sea marginalizada a través de su traducción de sí en la lengua de la mayoría, en este caso: el inglés. Por consiguiente, su argumento con respecto de aquel de Deleuze/Guattari está algo desplazado - desde la escritura hacia la traducción.

Si es que Deleuze/Guattari discuten sus tesis acerca de la literatura menor a propósito del ejemplo de los judíos de Praga y citan la observación de Kafka de un acceso obstruido a la escritura - los judíos de Praga habrían vivido entre "la imposibilidad de no escribir, la imposibilidad de escribir en alemán y la imposibilidad de escribir de otra forma" (24)-, entonces de esta situación derivan su tesis de las tres características de una literatura menor: primero, "desterritorialización de la lengua"; segundo, "acoplamiento de lo individual a lo inmediatamente político", porque en las literaturas menores "todo es político" y tercero, "encadenamiento colectivo de enunciados", porque en ello todo adquiere "valor colectivo" (25). Estas tres características también aplican al ejemplo del autor que escribe en escocés-gaélico. Y, sin embargo, su situación difiere en algunos aspectos. Con miras a la situación, en relación a la escritura, que Kafka había constatado respecto de los judíos de Praga, la poesía escocesa-gaélica ya sería un paso hacia afuera de la triple imposibilidad kafkiana, con lo que, sin embargo, el problema del acceso obstruido tan solo se desplaza: sobre la lectura, respectivamente, sobre la difusión -y, con ello, sobre la pregunta por la traducción.

Las reflexiones de White, que parten de sus propias experiencias, transcurren a lo largo de dos tramas argumentativas, una lingüístico-poética y otra político-cultural. La traducción de su poesía gaélica al inglés es algo

2 La lengua actualmente solo es hablada por $1 / 1 \%$ de la población escocesa que asciende a aproximadamente 5,4 millones. 
que siempre habría percibido como presión: "Nunca fue hecho con placer ni satisfacción" (67). Para él, la lengua del poema es lo esencial de la poesía, es, en cierto modo, el contenido de la lírica. Por lo tanto, considera a su traducción de sí como "una actividad sin contenido, vaciada de todos los ricos ecos e intercambios que hasta el momento he atribuido a la práctica de la traducción. Es casi un asunto de vaciar el poema de su contenido, que puede, de hecho, ser la lengua en la que fue escrito" (68). En la traducción de sí, según Whyte, la poesía es privada de lo más esencial que es suyo. Con el ensayo de Walter Benjamin sobre Hölderlin, esto se podría llamar "lo compuesto poéticamente" [das Gedichtete], "la esfera, particular y única, en la que residen tarea y condición previa del poema" (105).

La parte política de los argumentos de Whyte pone en juego la situación de los escritores en el exilio, así como la pregunta por la dependencia política: "Si la traducción trata sobre cruzar fronteras, contaminar una lengua con la experiencia y los ritmos del otro, entonces, la traducción de sí ocurre en situaciones de exilio o de subyugación cruda, donde una lengua intenta tomar el lugar de otra" (69). La traducción de sí, que, en cierto modo, desde la urgencia $[\mathrm{Not}]$ de la lengua minoritaria se convierte en necesidad, con tal de ser percibida, es, entonces, distinguida de la cultura de la traducción en general, con la que habitualmente la une la posibilidad de traspasar fronteras lingüístico-culturales y de poner en marcha un juego lingüístico infinito. Para el autor de una literatura menor, empero, el paso de encontrarse a través de la traducción de sí con el peligro de la marginalización, hace emerger otro tipo de marginalización. Esto se torna evidente cuando en Whyte se unen el aspecto poético y el aspecto político del problema. Así describe la imagen escritural, aparentemente inocente, de un libro como indicador de la relación hegemónica de las dos lenguas involucradas; como ejemplo nombra un libro bilingüe del escritor Sorley Mc Lean (1911-1996) y que escribe en gaélico, uno de los creadores literarios más importantes del siglo XX. En la correspondiente edición, según hace notar Whyte, la traducción al inglés está puesta al lado derecho, el lado dominante de la lectura, mientras que el original ha sido desplazado hacia la izquierda, con lo que esta poesía no tiene esperanza alguna de volver a emerger de sus dobles [Doppelgänger] furibundos. Porque "las versiones inglesas del autor, como si fueran dobles que, con gravedad evocadora e inquietante, a partir de las que sus poemas gaélicos ya no tienen esperanza alguna de ser puestas en libertad, ponen en riesgo la limitación y distorsión de la recepción de su trabajo" (71). La traducción de sí, así puede resumirse el artículo de Whyte, está lejos de ser inocente, porque siempre 
también está involucrada en relaciones de reciprocidad político-lingüísticas e incide en la constelación traductiva a través de la posición hegemónica de determinadas lenguas.

En la teoría de la traducción de sí, así como en las investigaciones de ciertos estudios de caso individuales, se suma de manera agravante el que siempre están determinadas por los conocimientos de la lengua extranjera, en cada caso específicos pero siempre limitados, de los investigadores particulares. El hecho de que hasta ahora la mayor parte de los aportes existentes concierna ya sea a traducciones desde el inglés o al inglés, es indicador de la creciente tendencia del inglés a convertirse en idioma global de teoría e investigación. Autores que escriben o traducen en otras lenguas rara vez aparecen en los debates sobre la traducción de sí ${ }^{3}$. Así, por ejemplo, la literatura de Yoko Tawada, que escribe en alemán y en inglés, y se traduce en ambas direcciones a sí misma, podría ser considerada como "bilingual laboratory" (Grutman y Van Bolderen 327) con el mismo derecho que la obra de Samuel Beckett, que desde hace décadas ocupa la posición de un caso ejemplar para la investigación. Si bien sobre la literatura de Yoko Tawada existe una extensa literatura de su comunidad de fanáticos continuamente creciente, pero hasta la fecha no ha ingresado a la teoría de las traducciones de sí.

\section{LA EMBLEMÁTICA FIGURA DEL 'TRANSLATED MAN’}

Una investigación sistemática de la traducción de sí mayormente partió a comienzos del siglo XXI. En tanto ámbito prominente de investigación aparece como una respuesta tardía al fenómeno creciente de autores bilingües y la literatura de autores que no escriben en su primera lengua, sino en la lengua mayoritaria del país hacia el que emigraron o en el que viven en el exilio. Aparentemente, este ámbito de investigación obtuvo su popularidad y significado en la estela de la teoría de la cultural translation; hoy está notoriamente influido por conceptos provenientes de los postcolonial studies, especialmente por la idea de las culturas, lenguas e identidades híbridas. La investigación existente consiste de un intensivo discurso teórico y de incontables

\footnotetext{
Una excepción a lo anterior es, por ejemplo, Witold Gombrowicz con la traducción de su novela Ferdydurke (1937) desde el polaco hacia el español (1947), en la que se comprometió un grupo de cientistas literarios argentinos (Grutman/ Van Bolderen 328).
} 
estudios individuales, estos últimos casi exclusivamente en el campo de la literatura. Durante mucho tiempo predominaron prominentes escritores de la Modernidad, sobre todo la terna de los traductores de sí más conocidos: Samuel Beckett (francés-inglés), Vladimir Nabokov (ruso-inglés) y Karen Blixen alias Isak Dinesen (inglés-danés) (Class 1250-52), seguido de Julien Green (francés-inglés), Joseph Brodsky (ruso-inglés), Raymond Federman (francés-inglés) y otros, mientras que recientemente el interés se ha dirigido hacia autores bilingües de procedencia no-europea, acaso los escritores de África y Sudamérica, así como autores con una así llamada identidad de guion. Estudios sobre la traducción de sí realizados por filósofos u otros científicos hasta la fecha son más bien escasos. Y justamente estos abren la posibilidad de comparar la transferencia de la lengua discursiva con aquella de la lengua poética o narrativa, acaso la transferencia de argumentos con la de metáforas, y de interrogar también el rol que en esto juegan distintos factores tales como la cultura lingüística y del pensamiento de los lectores a los que se dirige, el hábito académico, la estructura de la opinión pública, el mercado literario, etc.

La investigación contemporánea sobre la traducción de sí ha de ser localizada en la intersección entre la creciente relevancia del multiculturalismo, la migración y el postcolonialismo, por un lado, y el establecimiento, de parte de las ciencias especializadas, de la investigación de la traducción bajo el título translatology, por el otro. Esta es una posición no del todo aproblemática, desde la que emergen tensiones sintomatológicas: por un lado, la tendencia hacia la canonización típica de las disciplinas académicas, por el otro, una relación enfática con el paradigma del bilingüismo. En el centro de aquella terminología, tan programática como metafórica, se encuentra el ideal de lo híbrido - con el correspondiente efecto de una idealización tendencial de la traducción de sí. Un lugar clave en todo lo anterior lo ocupa el llamado 'translated man', equipado con la capacidad de una "double perspective" o una "stereotopic visión", como, hasta donde me consta, ha sido adoptada por vez primera por Salman Rushdie en su novela Shame (1983) y luego, otra vez más, en Imaginary Homeland (1992). Ahí caracteriza a la generación a la que pertenece como sigue: "Habiendo nacido a través del mundo, somos hombres traducidos" (17), una manera de dirigirse a sí mismo que con posterioridad se ha convertido en figura emblemática del discurso teórico. Porque la investigación lo sigue encantada. En un artículo sobre Rushdie, que lleva el título programático "Rushdie the translated man", Dana Bădulescu escribe: 
La traducción, al igual que la metáfora, es un viaje. Es el territorio cubierto por un viaje, un espacio entre aquí y allá, ni aquí ni allá. Entrando y saliendo de lenguaje, cultura y placer o, más bien, a través de ellos, el hombre traducido llega a un espacio híbrido, de disyunciones, escisiones y fisuras, que es franqueado, a modo de un puente, por la traducción y la metáfora. La condición de Rushdie como un 'hombre traducido' implica la traducción de sí. Todo texto traducido es un espejo del texto original. Los textos de Rushdie multiplican los espejos y el escritor traduce tanto como deja que sea traducido por las lenguas que habla (88; el destacado es mío, S.W.).

Ante el fondo de una traducción entendida como u-topos -"ni aquí ni allá"-, la traducción de sí se convierte en la solución ideal para sanar las heridas del exilio, respectivamente, de la separación del propio lugar, de la propia cultura y de la lengua materna.

Mientras que a comienzos de los años 1970 para George Steiner aún era evidente colocar sus reflexiones acerca de la relación entre exilio y lengua bajo el título Exterritorial, con tal de enfatizar el displacement geográficocultural, la dislocación o incluso expulsión, desde entonces, el discurso en la sucesión de la globalización y bajo el signo previo de la teoría postcolonial se ha desplazado radicalmente. La dominación del concepto de migración ha llevado a que la investigación de las respectivas condiciones históricoespecíficas y de la constelación lingüístico-política desaparezca tras el predominio de figuras del pensar teóricas y, con esto, también se eclipsa la pregunta por la manera en que, en cada caso, se motiva y conforma la partida del/la autor/a de su país de procedencia, de la propia lengua y cultura. Mientras que una persona en el exilio la mayor parte de las veces abandonó su país involuntariamente, al concepto de migración, en cambio, se asocian representaciones de partida, decisión y transgresión de fronteras buscadas, que le son atribuidas a un sujeto autónomo. Como efecto del desplazamiento del discurso desde el exilio hacia la migración se produce una especie de empoderamiento de la posición del autor-por muy imaginaria o fantasmática que ésta pueda ser de cara a la situación concreta de un(a) escribiente. Debido a su rol en las teorías de la traducción y la traducción de sí, puede constatarse que el paradigma de la migración tampoco es inocente. 


\section{SOBRE EL LUGAR DEL TRABAJO TRADUCTIVO - BILINGÜISMO Y REWRITING}

En el mismo trazo en el que el concepto de migración ha reemplazado aquel del exilio, se ha vuelto dominante el paradigma del bilingüismo. A pesar de que ejemplos de autores bilingües también en la fase inicial de los estudios de la traducción de sí jugaron un rol importante, desde aquel entonces se puede registrar una significativa revalorización. Es que al comienzo no estaban los "translated men", sino las alien tongues, así el título del influyente libro de Elizabeth Klosty Beaujour sobre Bilingual Russian Writers of the 'First' Emigration (1989). La investigación más tradicional con frecuencia consideraba a la traducción de sí como una tarea difícil, incluso como "tortura autoinfringida" (89f) que es mejor evitar escribiendo de inmediato en la segunda lengua, así Beaujour, que de este modo considera la lengua segunda como salida a los apuros y aprietos de la traducción de sí. En cambio, en la investigación más reciente $-\mathrm{y}$ en ésta el autor bilingüe se ha convertido en figura directriz de la traducción cultural-, la traducción de sí funciona como tropo con tal de marcar la posición de sujeto de un autor. Mientras que la teoría actual de la traducción de sí valora el bilingüismo como ventaja y ganancia, si es que no incluso como 'non plus ultra' de la traducción cultural, las investigaciones anteriores tendían a comprender la tarea del traductor como un esfuerzo por reparar o subsanar su déficit: con tal de ir al encuentro de la invisibilidad de la propia obra en un entorno nuevo o de franquear la distancia entre la lengua de la propia autoría y aquella del público lector de la gran literatura.

En el horizonte del bilingüismo, en cambio, las lenguas respectivas con frecuencia son puestas en una constelación de equivalencia, con lo que se nivelan la distancia, las diferencias y las eventuales asimetrías. Si es que la escritura en distintas lenguas se convierte en decisión libre o elección, entonces, en consecuencia, la extrañeza de las lenguas se convierte en algo secundario, al igual que las implicaciones históricas, culturales y epistémicas específicas, propias de cada lengua. Ya el bi en el bilingüismo supone una disposición similar de dos lenguas diferentes. De manera mediada, en cambio, se produce una equiparación de las distintas lenguas cuando se trata de nivelar la diferencia entre escribir y traducir o de captar la traducción como re-writing. Como en todo el discurso sobre la traducción de sí, también aquí Beckett representa el caso ideal. Mientras que el autor canadiense Paul St. Pierre, por ejemplo, que subraya la creatividad de las traducciones de sí de Beckett, llega a la conclusión de que el autor "socava la diferencia entre 
original y traducción, así como aquella entre escribir y traducir" y piensa a la traducción de sí como "escritura a través de lenguas" (242) y como un "proceso de escritura en camino" (244), Brian Fitch, en cambio, parte de una reciprocidad de las lenguas participantes. En su clásico ensayo Beckett and Babel. Investigation into the Status of the Bilingual Work (1988), interpreta la escritura de Beckett como proyecto de llevar a dos lenguas al estado de "reciprocal interference and interplay", "lo que no tiene nada que ver con aquel que la mera contigüidad de lenguas obtiene entre traducción y original" (134). Por lo tanto, es el autor bilingüe, mediante cuya figura se puso en juego una reformulación de la traducción de sí como re-writing, en parte con la consecuente conclusión de una reciprocidad de las lenguas.

La literatura de Yoko Tawada ( $c f r$. Weigel 2012; Brandt 2014; Weigel 2019) es, sin embargo, una especie de laboratorio bilingüe que permite mostrar que el infinito re-writing en la lengua alemana y japonesa justamente gana su particular creatividad desde la no-reciprocidad. Crecida en una cultura de lectura pictográfica, Tawada, que empezó a escribir en la lengua extranjera, literalmente le copió al alemán, recuperándolos, sus momentos ocultos, históricamente desaparecidos, de semejanza y magia lingüística. Con Benjamin, se podría decir que su mirada sobre la lengua extranjera vuelve a hacer perceptible a través de los sentidos la 'semejanza no-sensitiva/sensual' en el archivo de la lengua, al que la facultad mimética (Benjamin 204-213) ingresó en el curso de la historia cultural. En una especie de reacoplamiento, esta mirada temporiza sus efectos también en los textos de Tawada escritos en japonés, operando con la heterogeneidad de dos signos escriturales de la lengua japonesa kanji e higana que en cierto modo desconstruye los pictogramas procedentes del chino.

No es infrecuente que la idea de re-witing en el discurso teórico sirva al motivo de desprenderse del concepto del original. Así, en el artículo de Susan Basnett titulado "The self-translator as a rewriter" (2013) dice, por ejemplo:

El término 'traducción de sí' es problemático en varios sentidos, pero principalmente porque nos obliga a considerar el problema de la existencia de un original. La misma definición de traducción presupone un original en algún otro lugar, así que si hablamos de traducción de sí, asumimos que habrá otro texto previamente compuesto a partir del que el segundo texto puede afirmar su origen. Muchos escritores aún se consideran bilingües y se desplazan entre lenguas, por consiguiente la noción binaria de la traducción del original parece simplista y de poca ayuda (15, traducción propia). 
Este artículo es característico para la teoría más reciente en la que dominan topoi como re-writing, re-creation, re-enactment o double writing process; estos reemplazan las descripciones anteriores de la traducción de sí como "segundo original" o "nuevo original". En la correspondiente entrada "selftranslator" en la Encyclopedia of Literary Translation into English (2000), Kristine J. Anderson resume la discusión como sigue:

De acuerdo a algunas teorías, traducciones son metatextos -textos que interpretan y comentan el texto original. La traducción normal, en todo caso, es el resultado de un proceso biescalonado de lecturaescritura, mientras que la traducción de sí es un re-enactment del acto de escribir que produjo al primer texto. En otras palabras, traducción común y corriente es la reproducción de un producto, mientras que la traducción de sí es la repetición de un proceso. Tal como otros escritores han dicho sobre este asunto, la traducción de sí es realmente una re-escritura (1251).

La reformulación de la traducción de sí como re-writing o re-enactment aquí se presenta como figuración paradojal, ya que, por un lado, se desplaza la atención desde el producto, el texto traducido, hacia el proceso de la traducción, mientras que en su caracterización, por el otro, el trabajo del traducir es nivelada a través de su equiparación con la escritura.

Adicionalmente, en la delimitación entre la traducción de sí y la "traducción normal" que Anderson propone, esta última aparece bajo una luz problemática, a saber, como mera reproducción de un producto. ¿No debería comprenderse igualmente la llamada traducción normal como un proceso? Empero, con esto se plantea la pregunta de qué comprensión de traducción le subyace, en cada caso, al discurso de la traducción de sí -ya sea explícita o implícitamente. Un indicador de esta pregunta es el concepto del original, que aparece como un fantasma en el discurso de la traducción de sí. Con la precaria posición del original, la teoría de la traducción de sí hereda problemas de las llamadas teorías de la traducción normal, pero ello, cae incluso por detrás de reflexiones ya avanzadas.

\section{LO AJENO Y LA HETEROGENEIDAD INTERNA DE LAS LENGUAS}

Lo anterior se debe a que estas analizan la pregunta de la traducción ante el trasfondo de la pluralidad de las lenguas. Así, Derrida en Des Tours de 
Babel (1985) observó que las teorías de la traducción se encuentran con sus límites cuando únicamente cambian de una lengua a otra y no contemplan la posibilidad de que puedan estar involucradas "plus de deux", más de dos, en un mismo texto (215). Pero la pluralidad y la diversidad lingüísticas van incluso más allá de esta observación, debido a que estas ya conciernen a toda lengua individual. Las lenguas no son sistemas estables, unitarios u homogéneos, no son un registro de palabras o reglas. Remontándose a múltiples orígenes, cada lengua implica su propia heterogeneidad y sus elementos exófonos (Naguschewski, Arndt, Stockhammer). No solo que la diferente magnitud de heterogeneidad interna remite a la génesis específica de lenguas particulares, tal como Adorno en su ensayo "Die Wörter aus der Fremde" (1959) mostró a través del ejemplo del francés homogeneizado relativamente temprano y la lengua alemana homogeneizada relativamente tarde, sino que los elementos particulares de una lengua también tienen su respectivo índice histórico, en cada caso diferente.

En la traducción, la extranjería y la otredad internas de cada lengua se encuentran con la extranjería externa que existe entre diferentes lenguas. Dependiendo del índice histórico de un texto, su traducción implica múltiples operaciones traductivas: entre lenguas, tiempos, culturas, registros, idiomas, etc. en la traducción de sí el índice histórico de determinadas palabras, metáforas, figuras retóricas se mezcla con las connotaciones biográficas, subjetivas -con el resultado de una resonancia polífona de múltiples timbres, referencias y significados. Así es como Benjamin concibe a la traducción como "una forma de algún modo preliminar" de "vérselas reflexivamente con la extrañeza de las lenguas" (Benjamin, Die Aufgabe 14). De este modo, es la extrañeza de la(s) lengua(s) la que se encuentra en el centro de su ensayo "La tarea del traductor", no así la "mera lengua" [reine Sprache] (además que esta formulación en la traducción al inglés no es reproducida como 'mere' sino como 'pure language'). Y si Benjamin, adicionalmente, caracteriza la traducción como prueba del crecimiento de las lenguas y su distancia de un estado pre- o ahistórico, entonces la extrañeza concierne sobre todo a su signatura histórica. Cuando las lenguas, dice Benjamin,

se desarrollan así hasta el fin mesiánico de sus historias, la traducción se alumbra en la eterna supervivencia de las obras y en el infinito renacer de las lenguas, como prueba sin cesar repetida del sagrado desarrollo de los idiomas, es decir de la distancia que media entre su misterio y su revelación, y se ve hasta qué punto esa distancia se halla presente en el conocimiento" (14). 
Es decir, la extrañeza aquí no solo hace alusión a la diferencia, sino también a la distancia histórica. Por ende, Benjamin comprende la traducción como una discusión crítica con el condicionamiento histórico de la lengua, pero de seguro no como reproducción. Llama la atención que su ensayo, a diferencia de lo que ocurre en el paradigma de la traducción cultural, no opere con conceptos como transferencia, reemplazo, intercambio, interacción y otros. Más bien, la tarea de la traducción por él proyectada sensibiliza para significados y connotaciones ocultos. La extrañeza de la otra lengua, en cierto modo, saca a la luz, o le otorga audibilidad, a la extrañeza oculta de la propia lengua. Mientras mayor la extrañeza con la que se mira una lengua, de manera más poliestratificada, más recóndita, dotada de más trasfondos, ésta parece mirar de vuelta.

Desde esta perspectiva, la traducción posibilita una especie de despertar, respectivamente, una activación de significados latentes del original mediante la lengua ajena o también en ella, dependiendo del respectivo lugar del traductor. Esta relación, llena de tensiones, entre las lenguas, el original y la traducción es convertida, la poesía mediante, en una imagen del pensamiento [Denkbild] irisado:

Porque la traducción, al contrario de la creación literaria, no considera como quien dice el fondo de la selva idiomática, sino que la mira desde afuera, mejor dicho, desde en frente y sin penetrar en ella hace entrar al original en cada uno de los lugares en que eventualmente el eco puede dar, en el propio idioma, el reflejo de una obra escrita en una lengua extranjera (16).

En la medida en que al eco siempre le es propio una desfiguración dislocante [Entstellung] y la atmósfera específica del entorno en esto encuentra su resonancia, este pasaje reproduce con precisión el escenario de la traducción. El principio benjaminiano del eco representa la posibilidad de descubrir el sentido propio oculto de la lengua singular en el desvío por la traducción hacia el órganon del carácter histórico-culturalmente condicionado de la lengua involucrada. Esto es lo que Benjamin expresa cuando cita el trabajo de Rudolph Pannwitz sobre la traducción de textos griegos antiguos, resaltando que no se trata de convertir en alemán [verdeutschen] el griego, sino de "dar forma griega [vergriechischen] [...] al alemán" (20).

Pero, ¿qué es lo que se sigue de lo anterior para la traducción de sí? También a ella aplica que la extrañeza de las lenguas se encuentra en el centro. Las teorías de la traducción de sí pueden ser medidas según la posición que adoptan 
la extrañeza y el respectivo índice histórico de las lenguas participantes en esto. Si bien la distancia temporal entre escribir y traducir en la traducción de sí es relativamente pequeña, porque ambas ocurren al interior del tiempo de vida de uno y el mismo autor, pero las asimultaneidades culturales, políticas e intelectuales que acompañan el displacement geográfico-lingüístico del autor, juegan un rol relevante. Adicionalmente, la traducción de sí alberga el potencial de abrir los ojos, respectivamente, de aguzar los oídos, a través del desvío por la otra lengua, para características obviadas, ocultas de la lengua única. La traducción de sí implica la posibilidad de agudizar la lectura sintomática de los elementos individuales de aquella lengua sobre la que uno con frecuencia cree poder disponer de manera demasiado comprensible de suyo. Para autores bilingües que tienen la impresión de dominar ambas lenguas por igual y que suponen que su camino de la traducción está libre de las cortapisas de la ajenidad, esto demanda una atención incrementada. En este sentido, el bilingüismo puede resultar ser una trampa.

Quizá sea superfluo hacer notar que el trabajo con la extrañeza de las lenguas describe exactamente la posición contraria a la política traductiva dominante de la mayoría de las editoriales inglesas, al menos en el ámbito de las editoriales universitarias. Ante el trasfondo de que la opinión pública académica en un grado creciente tiende hacia el monolingüismo hegemónico, el principio normativo de una asimilación completa al idioma anglo-americano contemporáneo, el llamado 'proper English', tiene una serie de consecuencias para la historia intelectual de las humanidades. Porque con ello desaparece la dicción de la extrañeza, las huellas de la otredad y las signaturas de la historicidad de los textos traducidos -y con ellos la conciencia para lo anterior. En oposición a esto, no son pocas las traducciones al alemán de la teoría francesa, por ejemplo, el hacer especialmente audible y visible el eco de la particularidad en la dicción del respectivo autor -en ocasiones hasta la ilegibilidad (como en el caso de algunos textos de Lacan).

\section{EL FANTASMA DEL ORIGINAL Y LA TRADUCCIÓN SIN ORIGINAL}

Puede sonar banal, pero es fundamental: mientras que los pares conceptuales original-traducción y autor-traductor estructuran las reflexiones sobre la traducción, el objeto de la traducción de sí, en cambio, es otro, ya que aquí se trata de autor y traductor en una misma persona. En consecuencia, aquí 
todo gira en torno al juego conjunto o contrario entre escritura y traducción: es decir, por un lado, del escribir como actividad primaria, creativa, en el que pensamientos, recuerdos y fantasías son traídas hacia la lengua, generando y desechando formulaciones, buscando otras imágenes, palabras o argumentos; por el otro, del traducir como proceso de re-writing o de la reelaboración, es decir, del complementar, precisar, modificar, del tensar, condensar, explicar, etc. A pesar de que este trabajo en la escritura literaria transcurre de otras formas que en la modalidad escritural de ciencia y teoría, el original aquí juega un rol menos relevante que para los traductores profesionales, para los que el original está provisto de la autoridad de la autoría.

En los debates más recientes sobre la práctica traductiva, en cambio, se trata de una revaloración de la actividad del traductor y de su creatividad lingüística, que deben ser liberadas, en parte, de las cadenas de la dependencia del original. En esta agua de quilla, la autoridad y posición de supremacía tradicionales de la autoría y del original es tendencialmente relativizada -secundada por la destrucción postmoderna de la instancia del autor bajo la palabra clave de la muerte del autor (Barthes). Este debate también tiene sus efectos sobre el discurso de la traducción de sí, a pesar de que los respectivos conceptos aquí de facto son menos relevantes, debido a que en la doble posición de escribiente y traduciente se trata más bien de una autoría fuerte. El hecho de que varios aportes a la traducción de sí a pesar de ello lidien con el concepto del original apunta a un problema no resuelto.

Algunas investigaciones que siguen al concepto del re-writing de la traducción de sí, acaso como el libro de Fitch sobre el Beckett bilingüe, tienden a considerar al texto que fue escrito primero y a la traducción hecha por el mismo autor como meras "variantes" (132); en consecuencia, nivelan la diferencia entre escribir y traducir. Sin embargo, para aquellos autores que (aún) distinguen entre su lengua primera y una lengua segunda o extranjera, ambas lenguas se encuentran en una relación asimétrica. Estos casos se distinguen radicalmente, dependiendo de si el texto en un principio fue escrito en la lengua primera y luego transportado a otra lengua, o viceversa. E incluso para aquellos autores que crecieron de manera completamente bilingüe, las distintas lenguas cognitiva y emocionalmente están investidas de manera diferente, según los contextos personales y sociales en los que fueron aprendidas. Y, a pesar de toda la crítica de parte del debate en torno al género al concepto de lengua materna, la lengua de la madre biológica juega un rol decisivo para lo inconsciente lingüístico, debido a la enorme relevancia de la voz de la madre durante el desarrollo prenatal. En su sucesión, 
la incorporación del ritmo de la lengua precede, por ejemplo, al aprendizaje de la estructura sintáctica y del vocabulario.

Es particularmente complejo y, por consiguiente, de particular interés para las teorías de la traducción de sí, el caso de la traducción de un texto escrito en una lengua extranjera hacia la primera lengua. Esta praxis frecuentemente es calificada, de manera errónea, como 'retraducción', una idea que supone un texto hipotéticamente existente, pero invisible, que precede virtualmente a aquel escrito en la lengua ajena o secundaria. En esto, el original es proyectado hacia una inaccesible esfera del interior donde supuestamente lleva una existencia fantasmática: como pre-texto hipotético, que precede a la generación de la lengua. En una investigación acerca de las traducciones de sí de Klaus Mann, Stefan Heym, Rudolf Arnheim y Hannah Arendt, por ejemplo, Verena Jung presupone una "versión del lenguaje interior del original inglés, que precede al proceso de escritura" (530; cfr. también Gössmann). Esta idea de un 'texto interior' corresponde al presupuesto de significados prelingüísticos, pero ya distintivos, que ahora tienen que ser transferidos en palabras, mientras que a más tardar desde Saussure le es atribuido un rol constitutivo al lenguaje en cuanto a la generación y formulación de ideas. En relación a la traducción de sí, la construcción de un texto interior ocupa el lugar de un 'original verdadero', con lo que el texto inglés es desplazado hacia una posición secundaria, una especie de original inauténtico, mediado. Partiendo de una posición prioritaria aparentemente eterna de la lengua primera, de esta manera cada texto redactado en la lengua secundaria en cierto modo se convierte en un original desfigurado. Su curación acontece por el desvío de la traducción de sí en la lengua primera del autor, una especie de repatriación y transformación en un original auténtico, que desde siempre existió en un estado mudo, preverbal, esperando ser despertado.

\section{TRADUCCIÓN SIN ORIGINAL}

En oposición a semejante construcción propongo tomar en serio el efecto retardado [Nachträglichkeit] y convertirlo en punto de partida de una teoría alternativa de la traducción de sí. Con referencia a la descripción del sueño como 'traducción sin original' en el psicoanálisis lacaniano (Weber 5), la escritura puede comprenderse precisamente como traducción sin original, es decir, literalmente como escribir de otro modo, respectivamente, como escribir en otra lengua. En esto no es infrecuente que los autores no pueden 
tener certeza absoluta de moverse como amo en la casa de la lengua, o sea, los signos de las significaciones; con frecuencia no tienen claridad de si, en las formulaciones individuales resuenan insospechados semitonos, matices o tonos intermedios. A diferencia de la herida narcisista infringida por el psicoanálisis a partir de la introspección de que "el yo no es amo en su propia casa" (Freud 11), esta inseguridad no emerge a partir del propio inconsciente. Procede, más bien, del inconsciente lingüístico, de la familiaridad tan solo relativa con las polisemias y matices de una lengua extranjera, con las connotaciones, contextos y tintes de sus palabras, formulaciones o giros individuales. Siempre y cuando esto es el caso, la traducción de sí hacia la lengua primera no solo puede ser comprendida como re-writing, sino también como proceso de elaboración: como elaboración de formulaciones, metáforas y conceptos, de argumentos, ejemplos y explicaciones.

Este trabajo puede describirse, en analogía a la técnica freudiana, bajo el lema "Recordar, repetir, elaborar". Mientras que el recordar aquí concierne a la pregunta por el temprano deseo de expresión, que motivó ya sea al texto existente o a algunas de sus oraciones, escrito en un momento temprano en la lengua extranjera o secundaria, no obstante, este proceso del recordar está marcado por el deseo reciente de expresión y la situación actual de traducción -de manera semejante a la constelación analítica. Porque la situación actual del autor-traductor -por así decir, el (tiempo del) ahora [Jetztzeit] de la traducción de sí- arroja anticipadamente su luz sobre el proceso precedente del que escribe de otra forma.

Un ejemplo destacado para lo anterior es la teoría política bilingüe de Hannah Arendt (Goebel y Weigel, Poetic difference). Luego de que, pocos años después de haber llegado a EE.UU. en 1942, haya empezado a escribir en inglés, Arendt desarrolló una manera de escribir que, siguiendo a Benjamin, puede describirse como saber de los umbrales [Schwellenkunde], justamente no "neither here nor there", sino, de lo contrario: aquí $y$ allá, a sabiendas de las distintas culturas lingüísticas del pensamiento político en la lengua angloamericana y alemana. Sus traducciones de sí son el resultado de la reflexión sobre traductibilidad e intraductibilidad en la transferencia entre lenguas diferentes: entre el griego, el alemán y el inglés, entre lengua poética, reflexión filosófica y el idioma de la teoría política, entre conceptos antiguos, metáforas y conceptos modernos. Un producto de la constante sobreescritura, en la que las diferencias entre sus textos ingleses y alemanes pueden ser leídas como eco de la letralidad [Buchstäblichkeit] en el trato con conceptos, retórica y metafórica en la lengua teórica. 
Las diferencias que se producen en este proceso entre el texto científico escrito en inglés y su traducción de sí al alemán, pueden ser interpretados como respuesta a los distintos estilos lingüísticos y del pensar de los lectores a los que se dirigen, a veces también como síntomas de lugares faltos de claridad, no esclarecidos o ambiguos en el primer texto, que motivan una precisión en el segundo texto. Así, no es infrecuente que los textos de Arendt, autotraducidos hacia su primera lengua, sean más extensos que los textos correspondientes que originalmente fueron redactados en la lengua extranjera.

Las Momentaufnahmen/Instantanés del cientista literario franco-isrealí Stéphane Mosès (2010) muestran cuán fuertemente la traducción de sí puede forzar el proceso del recordar. Las escenas recordadas que comenzó a escribir en alemán, la lengua del país del cual fue desterrado a los seis años, y que transcurren en Berlín y en el exilio marroquí, terminan casi simbólicamente con su naturalización en 1949 en París, a su vez, el nacimiento de su nombre francés de autor, mientras que la sucesiva traducción de sí al francés no solo puso en marcha el que siguiera escribiendo el texto en francés, sino que también motivó la elaboración y complementación de las escenas presentes con imágenes del recuerdo con un contenido afectivo y problemático sintomáticos. En el resultado, el texto francés consiste en algunas escenas autotraducidas, elaboradas y otras, formuladas en francés.

En el caso de textos poéticos, en cambio, las diferencias pueden ser el resultado de un continuo juego creativo de lenguaje que se alimenta de las diferencias, nuevamente descubiertas, entre las lenguas participantes. No obstante, en todos los casos de esta forma de traducción de sí en ningún caso se trata de reconstruir ni reproducir un texto anterior, sino de la sobreescritura de un texto, escrito en la lengua extranjera, con el texto elaborado en la lengua primera. El resultado de un repetido elaborar, que siempre acompaña el trabajo de la traducción de sí, se encuentra en oposición diametral a la construcción de un objeto pre-existente. Más bien se trata de un proceso, en el que el efecto retardado resulta ser posibilidad del sobre y reelaborar: la traducción de sí como sobreescritura y reescritura. Aquellos autores que practican el escribir en la lengua extranjera y la traducción del texto propio en su lengua primera, sacan enorme provecho de esta forma del re-writing permanente: los autores de textos discursivos al especificar aspectos singulares, precisan o explican, mientras que los escritores literarios pueden desarrollar aún más la creatividad lingüística de su literatura y obtener dimensiones adicionales de su propia lengua. 


\section{BIBLIOGRAFÍA}

Adorno, Theodor W. "Wörter aus der Fremde". 1959. Noten zur Literatur Frankfurt/M.: Suhrkamp, 1981. 216-232.

Anderson, Kristine J. “Self-Translators”. Ed. Class, Olive. Encyclopedia of Literary Translation into English, vol. 2. London, Chicago: Fitzroy Dearborn Publishers, 2000. 1250 -52.

Bădulescu, Dana. "Rushdie the 'translated man"”. Sfera Politicii. Revista de Stiinte Politice. Editata de Fundatia Societatae Civila. Num. 12 (166) on Migratia. Noile dimensiuni ale unui vechi fenomen (Dec. 2011): 87-96.

Barthes, Roland. "La mort de l'auteur”. Le bruissement de la langue. Paris: Seuil, 1984. 61-67.

Basnett, Susan. "The self-translator as rewriter". Ed. Anthony Cordingly. Self-translation: brokering originality in hybrid culture. New York: Bloomsbury, 2013. 13-26.

Benjamin, Walter. "Lehre vom Ähnlichen. Über das mimetische Vermögen”. Gesammelte Schriften. Eds. R. Tiedemann/ H. Schweppenhäuser, tomo II. Frankfurt/M.: Suhrkamp, 1980. 204-213.

"Zwei Gedichte von Friedrich Hölderlin". Gesammelte Schriften. Eds. R. Tiedemann/ H. Schweppenhäuser, tomo II. Frankfurt/M.: Suhrkamp, 1980. 375-400.

"Die Aufgabe des Übersetzers". Gesammelte Schriften. Eds. R. Tiedemann/ H. Schweppenhäuser, tomo IV. Frankfurt/M.: Suhrkamp, 1980. 204-213.

Brandt, Bettina. "The Bones of Translation. Yoko Tawada's Translational Poetics". Thamyris/ Intersecting: Place, Sex and Race. Challenging the Myth of Monolingualism. Eds. Liesbeth Minnaard/Till Dembeck. Amsterdam-New York, NY: Rodopi B.V., 2014. 181-194.

Deleuze, Gilles y Félix Guattari, Kafka. Pour une littérature mineur. Paris: Les Editions Minuit, 1975.

Derrida, Jacques. "Des Tours de Babel". Difference in translation. Ed. F. Joseph Graham. London, 1985. 209-248.

Fitch, Brian. Beckett and Babel: an Investigation in the Status of the bilingual Work. Toronto: University of Toronto Press, 1988.

Freud, Sigmund. "Eine Schwierigkeit der Psychoanalyse". Gesammelte Werke, tomo XII. Werke aus den Jahren 1917-1920, Frankfurt/M.: Fischer 1999. 3-12.

Gössmann, Wilhelm. "Das literarische Schreiben als Zentrum von Schreiberfahrungen". Schreiben und Übersetzen. Tübingen: Narr, 1994. 11-29.

Grutman, Rainier and Trish Van Bolderen. Self-Translation. A Companion to Translation Studies. Ed. by Sandra Berman and Catherine Porter. New York: John Wiley \& Sons, Ltd., 2014. 323-332.

Jung, Verena. "Written Germany in Exile - the Bilingual Author as Cultural Mediator: Klaus Mann, Stefan Heym, Rudolf Arnheim and Hannah Arendt". Journal of Multilingual and Multicultural Development 25.5/6 (2004): 529-546.

Klosty Beaujour, Elizabeth. Alien Tongues: Bilingual Russian Writers of the 'First'Emigration, Ithaca, London: Cornell University Press, 1989. 
Mosès, Stéphane. Momentaufnahmen/Instantanés. Alemán y francés. Ed. Sigrid Weigel. Berlin: Suhrkamp, 2010.

Naguschewski, Dirk; Susan Arndt y Robert Stockhammer. Eds. Exophonie-Anders-Sprachigkeit (in) der Literatur. Berlin: Kadmos, 2007.

Olive Classe. Ed. Encyclopedia of Literary Translation into English, London, Chicago, 2000, vol. 2. 1250-52.

Rushdie, Salman. Imaginary Homelands, Essays and Criticism 1981-1991. London: Penguin Books, 1992.

Shame. London: Jonathan Cape, 1983

St. Pierre, Paul. "Translation as Writing Across Languages: Samuel Beckett and Fakir Mohan Senapati”. TTR: traduction, terminologie, rédaction Vol. 9, n 1 (1996): 233-257.

Weber, Samuel. Rückkehr zu Freud. Jacques Lacans Ent-stellung der Psychoanalyse. Frankfurt/M, Berlin, Wien: Ullstein, 1978.

Weigel, Sigrid. "Poetic difference - sounding through - selftranslation. Hannah Arendt's Thoughts and Writings between different languages, cultures, and fields". Eds. Eckart Goebel/ Sigrid Weigel. 'Escape to Life'. German Intellectuals in New York. A Compendium on Exile after 1933. Berlin/Boston: De Gruyter, 2012. 55-79.

"Suche nach einem E-mail für japanische Geister. Yoko Tawadas Poetik am Übergang differenter Schriftsysteme". Ed. Yoko Tawada. Fremde Wasser. Vorlesungen und wissenschaftliche Beiträge. Ortrud Gutjahr. Tübingen: Konkursbuch Verlag, 2012. 127-143.

"Yoko Tawada's Poetics on the Threshold of Different Writing Systems". Ed. Doug Slaymaker. Yoko Tawada. On Writing and Rewriting. Minneapolis: Lexington Books, 2019. 49-59.

Whyte, Christopher. "Against Self-Translation". Translation and Literature, vol. 11, part 1, (Spring 2002): 4-71. 